\title{
CHANGING VALUES IN THE EAST
}

\author{
Kali PRASAD \\ India International Center, New Delhi
}

The traditional structure of values and the philosophy of life associated with it may be illustrated by taking different countries in the regions of South Asia and Far East. A crosscultural and comparative research concerning this problem has not been attempted so far. With the emergence of independence in this region and consequent facility of communication as also the need for understanding and appreciating the attitudes and values of the people ih this large area, a research of this kind has acquired an urgency today. In this context we may view the Unesco Major Project of Mutual Appreciation of the Cultural Values of East and West and take up the problem in the manner formulated below. The scheme suggested here refers to our country but mutatis mutandis it could be applied to the whole region of South Asia and Far East. It is hoped that this research would be taken up in different Centers of the region so that comparative data and results could be available. The value of this research itself lies in developing awareness and understanding which are basic to mutual appreciation of cultural values.

INDIA:

\section{Sources of Values}

Scriptures and classics - (a) Vedas (b) Aranyakas (c) Upanisads (d) Srauta and the Grihyasutras (e) Dharma Shastras (f) Epics (g) Puranas (h) Agamas.

The traditional values enjoined in the above are centred around the concepts of Dharma, Artha, Kama and Moksa.

Dharma - Dharma implies the values of:-

i) Tolerance, ii) Ahimsa, iii) Freedom

The term Dharma (Dhri-ma: to hold fast) means the law that sustains or natural justice. There are minor variations in the usage of the term in various texts e.g. in Rig Veda, it is sometimes used in the sense of Customs (Kul Dharma, Desh Dharma etc.). In the Dharma Shastras it is used in the sense of laws that maintain the social order. In Kathopnishad (ii, 14) it means religious sacrifice. In Ethics it means principles based upon divine laws. Underlying all these conceptions is the main concept of law of natural justice or the regulative principles of conduct in life. In this sense the ideal of Dharma implics the 'Ultimate or Eternal Law' which orders life and nature. Though there may be different traditions and customs organizing different societies there is a basic principle, the Dharma which underlies and regulates them all.

According to Manu-Smriti there are ten characteristic marks of Dharma: 1. Dhriti (Steadiness, Self possession, Self command, balancing); 2. Kshama (forgiveness, tolerance); 3. Dama (Suppression or Sublimation); 4. Asteya (Non-stealing, non-appropriation); 5. Shaucha (Purification, purity, uprightness): 6. Indriyah - Nigraha (Sensory Control); 7. 
Dhi (Discriminatory intelligence); 8. Vidya (Knowledge); 9. Satya (Truth); 10. Akrodha (Absence of anger). Yajnavalkya omits Dhriti, Dhi, Vidya and Akrodha and adds Ahimsa (Non-violence); Dana (Charity, generousity); Daya (kindness, sympathy) to the above list. This illustrates the fact that the concept of Dharma is not fixed or unchanging; it has undergone modifications according to varying social and political conditions of the country. It also changes according to Yugas -. Time cycle-understood both in the cosmological as well as psychological senses. (It must be remembered that there is a psychobiological interpretation of the yugas according to which different periods and conditions of individual life require appropriate Dharmas. For instance, where Satva dominates we call it Satyuga and similarly with the rest. This means that the Yugas depend upon human powers of organization of social-political affairs and are not to be considered eternally fixed space-time points).

A further illustration of the flexibility of the concept of Dharma is to be found in the concept of Apatdharma according to which when one's life is threatened one may give up the traditionally sanctioned Dharma in favor of conduct which is normally not approved e.g. a Brahmin may resort to begging when he is threatened with starvation and similarly for some other caste groups.

A great value is placed upon Dharma as a preserver of individuality. The Gita expounds the concept of Swa-Dharma i.e. the performance of one's duties in conformity with one's position and station in life. Since the ultimate aim is self-realization, the individual is free to order or organize his life in any manner that is consistent with this end. This implies the necessary value of tolerance and respect for others and the related concept of Ahimsa (Nonviolence). It also presupposes freedom. It is interesting to observe here that throughout the long history of Hindu India there has been no violent persecution on the ground of religious differences. The concept of Dharma makes both for pursuit of one's duties in one's social milieu as also for adjustment, accommodation and tolerance for others' ways in achieving the same. This explains the great catholicity and openness of the Indian mind which while it might be conservative in regard to its customary, ritualistic living (Dharma) it is extremely free and open in respect of ideas and thinking. This has allowed different cultural strains to mix and mingle throughout the long history of the country and to present today the panorama of a kaleidoscopic pattern of beautiful hues and colors. And yet behind all this diversity there is the regulative principle of Dharma which holds the different strains together in the context of our philosophy of life-a philosophy which emphasizes again and again the ultimate goal of self-realization or realization of Brahman.

Artha

Artha or material welfare means and includes the following values:

i) Acquisition of wealth

ii) Aprigraha (non-appropriation)

iii) Asteya (non-stealing)

There is a common misconception that acquisition of material goods is not consistent with Indian Values and philoscphy of life. But the dominant aspect of this philosophy which is idealistic in its outlook does give adequate room for material acquisition on Earth. Here a distinction of ends and means is made. Since the ultimate end of life is the realization 
of the indivisible unity of the Brahman all the activities of the individual must be directed toward the attainment of this end. In this context the material environment has to be so organized as to serve this purpose and to the extent that it does so it is not only not to be despised but is essential for the end. When the life of matter becomes possessive and threatens to crowd out the life of the spirit it must be restrained or even abandoned. In essence this is also the teaching of all religions: Buddhism and Christianity emphasize the same. (It is easier for the camel to pass through the eye of the needle than for, the rich to enter the Kingdom of Heaven' - Bible). The philosophy of Gita and Upanishads as also of Vedanta suggest the same view. For instance, when the Advaita Vedanta says that Brahman is the only Reality and all else is an appearance (Maya), it emphasizes the immanence and the pervasive character of this Reality; it does not deny materiality or appearance. The Seers or those who know understand that the whole world and the Cosmos is merely a cloak or an Adhyas (Supcrimposition) which masks the Real. One has to tear down this mask in order to come face to face with the refulgence of the ultimate Reality. The question why this mask, ignorance or avidya is answered by Samkara by pointing out that this 'question' itself is a psuedo-question, since it does not arise at all when the seer has attained knowledge of the Real. Just as the adult looks upon the period of his infancy when his play-things or toys constituted the sole fabric of reality as a thing of past and unreal at present, so also the material adjuncts of life are incidental accessories which do not possess substantial reality.

According to this interpretation of the material world -- and interpretation which constitutes a dominant aspect of our philosophy, the acquisition of naterial goods is an important value because it provides the ground or raison d'etre for the operation of the spirit. Hence it would be clear that renunciation may not be understood in the negative sense of rejection but in the positive meaning of taking an attitude of detachment or objectivity. One has to guard against an undue involvement with the material things. But one must acquire those things and cultivate the attitude that they are a means toward the ultimate and, not the end itself. This is the meaning of Vairagya which is a positive attitude toward the material things not an attitude against them. It would seem then that around the concept of Artha revolve the values of acquisition of wealth, Aprigraha and Asteya.

Kamia

Kama or creative energy implies the values of:

i) Creativity (Activity); ii) Achievement; iii) Innovation; iv) Self restraint (Brahmacharya).

Kama is the source of all action without which the aims of Dharma and Artha cannot be fulfilled. All the five senses function in view of Kana for it is basic to all activity and is more important than Artha. It is not to be used in a narrow psycho-biological sense but in the wider context of the main course from which all activity springs. The activity of Kama has to operate in the framework of Dharma and in the interest of Artha. There are three types of Kama - (1) Extemal (Vahya, sthoola); (2) Internal (Antarika); and (3) "Refined" (Sukshama). This clssification includes the customary meanings of the term used by psychologists and psychoanalysts and also draws attention to certain peculiar nuances connected with use of the term in classical Indian psychology. The latter meaning emphasizes the pervasive, energic and creative character of Kama-by virtue of which the sensory-- 
perceptual as well as the emotional intellectual dimensions of the whole man secure satisfaction. In this sense Kama is considered even more important than Dharma and Artha. Moksa

Moksa includes the values:

i) Vairiagya (renunciation or non-involvement); ii) Desire and effort for perfection; iii) Aprigraha (non-appropriation.)

The concept of. Moksa stresses the value of objectivity and non-involvement. In order that an individual is able to attain the fullest development of his personality i.e. the realization of his ultimate nature, he must procced toward this ideal by a process of non-identification with the various stages through which he passes. This does not mean that he should be oblivious to his duties toward his fellow-men; on the contrary, he can perform his duties most successfully when he has acquired the attitude of detachment and objectivity. It is well-known that the goal is best achieved when one is not thinking of it all the time. The acting person acts in his world without being overwhelmed by it. He is in it though not of it. Hence, renunciation is not a negative concept; it is a positive attitude towards its assessment - an assessment which implies non-involvement. In this sense as we proceed from one stage or segment of life to another, we go on progressively acquiring Moksha until ultimately we acquire the state of, what is known as, Jeevan Mukta. Moksha also means freedom from birth and rebirth which implies emancipation of the individual from all that cramps his personality fulfillment by breaking the bonds that fasten him to a narrow and insular existence. He dies with reference to these and is "born" again to a new life for the flowering of which he must engage himself in activity. This would seem to be the essence of the theory of rebirth as also of transmigration. (Obviously this is no place for a full psychological interpretation of this concept.) One must emphasize that the concept of Moksa does not preach a barren other - worldiness but the cultivation of an attitude which would made for a life of successful endeavor as the highest value.

\section{Traditional Values under Stress}

The atomosphere in which the Indian mind has grown and developed has given it a characteristic pattern. The most significant dimensions of this pattern are:

1. Its capacity for contemplation and sometimes speculative flights into the realm of unseen and unknown.

2. Its remarkable capacity for apprehending unity in diversity - a capacity impatient of isolated details which it tries to subdue into harmony and an over-riding unity. The attitude of this mind towards nature, its geographical and ecological environment is marked by seeking harmony and sympathetic co-existence. This is probably due to temperate climate, rich soil and abundant production and lack of pressure on material resources. All this has led to the development of agriculture and rural craft. In other countries where the geographical environment is not so hospitable, where man has to struggle against nature the altitude is not necessarily that of harmony but of "conquest." For this reason man in this country has not been against or over nature, but in harmony with nature. This has also led to the development of an attitude which favors gradualness (evolution) as against sudden- 
ness or jerks (revolution) as in some other countries. In addition to these there are other factors different from physical, economic or political which have conditioned the growth of the Indian mind and which are more fundamental. These are its ideational conponents i.e. ideas, beliefs and principles which have their origin in the consciousness of the higher values. These ideational elements are not necessarily the products of the soil. They have sometimes originated elsewhere but have influenced the people of this country in different times and different degrees.

In the early beginnings of our history we find that the pre-Aryan influences affected the Aryan mind and gave rise to what has been called the Vedic Culture. After a time there was a reaction against certain aspect of this culture and Buddhism sought to introduce a corrective. Although the influence of Buddhism has been deep on the Indian mind, the culture associated with it has not produced a lasting effect. Its decay was followed by the rise of a new Hindu. Culture which has been distinguished from the early Vedic culture as Puranic Culture. At the end of the 7th Century Muslim influences began to be felt and by the 15th Century Muslim rule had established itself in the country. During the 18th and 19th Century the British influence dominated the political scene. Unlike the Muslims who had come and settled themselves in the country adopting and adopting its institutions the British remained an external element and never tried to integrate with the life and culture of the people. In consequence, while the impact of Muslim culture and values affected Indian life in multitudinous ways and helped the rise of a rich composite culture, the British influence remained peripheral throughout and helped only in emergence of what has been called the English Colonial culture-a culture which gave rise to a strange species, neither Indian nor English but a monstrous phenomenon symbolized by Macauly's Babus with their grotesque accents of foreign language and foreign dress who helped as agents of the British Imperial Rule for more than two centuries. It was unfortunate that the English Colonial Culture sought to introduce itself through the machinery of the British Government and was consequently suspect all the time because it was not genuinely western nor even genuinely British. As a reaction against this situation when the Indian Independence came we adopted the ideal of secular democracy wedded to no religion at all.

During all these centuries of change and stress while the fundamental fabric of our thinking (analytical, contemplative attitude, Unity-diversity component) has remained relatively unaltered our attitudes and values have undergone varying degree of shift and modifications.

\section{Problems for Research}

In many ways we are all conscious of this. Our economic life, political system and certain aspects of social structure and organization bear the testimony to the process of change. We have a number of descriptive and impressionistic accounts of this change but a valid scientific and objective study is hardly available. There are undoubted difficulties of which the colossal magnitude of the problem and the lack of background data are only two which may be mentioned. But an experimental investigation, even a pilot 
study of the change and the shifts that have been taking place in our value structure would appear to be necessary for atleast two reasons; (1) With the adoption of industrial democracy as a political system we have to understand and to see to what extent the values associated with this system, as for instance, found in Western industrialized countries, are congruent with the values of our traditional structure as described above; (2) Once we have made a scientific study of this aspect we should be able to assess adequately whether the steps that we are introducing secure (or do not secure) modification of these values. This would enable one to measure the rate of change and possibly also to accelerate it.

To illustrate there are certain specific problems concerning a modern man's life which may be mentioned here:

1. To what extent is it a man's responsibility to control his own destiny? This raises the question how the common man's belief in his destiny, Prarabdha, affects his achievement motive and performance. Do we have high or low achievers in families where this belief is dominant? To what extent does it direct and control activities in various fields: Education, business, social affairs, etc.? How does this belief correlate to educational and socio-economic status of individuals or groups concerned? To what extent does it hamper initiative and occupational or status mobility?

2. The importance of loyalty to a larger group than the family - to the region, to the nation, country or to the world as a whole. Does noe's value of loyalty dictate preference to the family welfare compared to the interests of a larger whole? In other words how often is one justified and in what circumstances to sacrifice his own interests and that of his family for the sake of the larger collectivity. If one's values are rigid enough to require advancement of family welfare in preference to larger groups then his fitness in a democratic social structure will be doubtful.

3. Does a man's actual performance in a large impersonal system constitute the basis for determining his prestige and influence? Or, are the latter due to his inherited status as distinct from his achieved status? Do prestige and power accrue from competence and individual efforts and enterprise rather than from established connections? How does our value system accommodate (or does not) individual effort as compared to inherited influence?

4. Is the traditional power and authority structure in the family being modified in the present social and economic conditions? What are the major characteristics and directions of this modification? How is power and authority of the parents affecting the children? Do powerful fathers tend to produce sons of low achievement - values with a belief in destiny beyond their control and an unwillingness to leave home? To what extent is the value of obedience to parents undergoing change? If the mother's power is stronger then is the son likely to have higher achievement - values (as in U.S.A.)? If he lives in an autocratic authoritarian atmosphere in the family does the child transfer the same to life outside? On the contrary, if he lives in a democratic atmosphere how far does he transfer this outside?

5. Is a rigorous life of minimum wants to be preferred to a life of comfort and case? Do not material goods corrupt the soul: Should one withdraw from the bustle and excitement around or should one launch on a life of energetic activity with a view to 
changing the nature of the world and social order?

6. How does education and uphringing affect the 'stable preferences' or the values? What is the extent of modification in the attitude of the educational classes toward the traditional values? What is the pattern of new values (if any) adopted by these new classes? Do these classes have any impact on the masses? To what extent would the educated or scientific elite provide a lead to the people? All these need to be investigated in a scientific way.

7. Has the adoption of modern technology associated with industrialization produced any change or modification in the traditional structure of our values? To what extent has sanctity of any work as such has been accepted as such: How far decp-rooted is our faith in standardization, efficiency, cooperation and sanctity and equality of individuals? To what extent do we believe that material prosperity secured by industrialization fulfill the real aim of life? Do we not have a fear that ultimately material prosperity would lead to the impoverishment of the soul? Is there not a lurking faith that withdrawal from the material scene is the only way of achieving self-realization? Questions like these and others need detailed investigation and research.

What are the ways of modifying stable characteristics of persons or situations i.e. their value systems? How far (if at all) is direct conscious teaching likely to change the needs and values fundamentally: Does not conscious teaching merely change the expressions of values rather than their content? What is the role of indirect methods of changing value systems? And what are those methods in the present-day context?

A programme of intensive research has to be initiated with a focus on problems concerning the decisive part that values play in determining attitudes and behavior in a culture-pattern. This research may be organized at two levels: (1) A discussion and analysis of certain basic theoretical concepts like space-time-movement (as against its absoluteness as a category, the consideration of the concepts of quasi-physical, social, conceptual facts in life-space; sidereal, zoological, historical time and their social-cultural consequences); social reality; manipulability of human nature; social order; technical change; regression and resistance; fragmentation of personality; language and the communication process, etc., etc. These concepts have to be discussed in the light of recent revisions of the theories of space-time and th: character of the expanding universe and the new man. The new concepts entail a revision of the foundations of sociological theory.

It would also require suitable theoretical 'models' for social science. An important question in this regard has been raised as to whether the orthodox physical-mathematical model upon which social sciences have been so far based (like the natural sciences) is appropriate for dealing with the phenomena of the dynamics of human interactions; whether perhaps a psycho-biological model (as adopted in social psychology) is not mere appropriate. Also, whether the excessive reliance that is placed on statistical and survey methods does not merely produce impressive but sterile array of so-called 'facts' which ignore the essential dynamical qualities of human behavior. (2) The second type of research would consist in preceding from a certain assumed theoretical base to the construction and testing of hypotheses (such as the one proposed in this paper). Broadly two experimental designs may be used which would complement each other. In the person- 
ality experiment trait clusters technique which would also include the use of stereotypes would be employed and data obtained from stratified random samples. The stratification would include populations from various regions distributed at different levels of industrialisation from the most highly to the least industrialised areas. There would be appropriate control groups for these. Inter-correlations between various 'types' of individuals and between various character-traits would be worked out. Once scores are obtained on the traits, the individuals (or a cross-section of them) may be given certain other tests like a projective test and later on interview. The interview may be a non-directed type preferably clinically oriented. Data on these tests and the interview would be checked for reliability and final scores made.

After this (or along with and even independently of the first) the value-experiment may be organised. This would use the same sample. Here a particular value-polarity may be graduated on a five-point scale and scores obtained on several of these value-continuum. They would be supplemented as above by non-directed clinically oriented interviews. Cross correlations between the results of the two experiments would be worked out.

\section{Design of Research}

This value study could be organized in at least four regions in the country - 1 . Delhi, 2. Madras or Mysore, 3. Ahmedabad or Bombay, 4. Cauhati.

The sample studied would consist of stratified random groups and the number may be 1,000 individuals at cach of the four countries. The stratification would include various important occupations, castes, variables like education, income, place of residence (rural, urban), sex, etc.

The methods and techniques of investigation would include:

a. Value Questionnaire consisting of statements bearing on values such as (1) human planning hardly matters because there is a destiny that shapes our ends; (2) nothing in life is worth the sacrifice of moving away from one's home and parents; (3) today we need more law and social authority and the individual should learn to subordinate himself to social regulation; (4) whatever one might say the higher castes exercise the real influence in shaping the policies of the country for they alone hold real power.

b. Projective tests Our T.A.T.; incomplete sentences; story interpretation, etc. may be used. The projective tests are a device to bring out attitudes and beliefs which operate unconsciously in the individual's behavior and which determine his goals. The techniques used here enable one to get at the unconscious ideas, images, beliefs and drives.

c. Interviews Two types of interviews, the directed and the nondirected would be used and also interview will be prepared to supplement the Questionnaire.

d. Experimental manipulation of attitudes by using audio-visual aids, film strips, psychodrama, etc. This may be illustrated by well known technique of measuring attitude change by exposing experimental groups to one or more of the above methods.

A number of statistical operations will be required specially in connection with sampling and analysis of data; including factor analysis, analysis of variance, etc.

In addition qualitative analyses consisting of content analysis, scalogram analysis, latent 
structure analysis, etc. and interpretation of T.A.T. pictures and of other projective techniques will be made.

\section{The Value of This Research}

The importance of this research lies as has been indicated above in ascertaining (1) scientifically the trend (if any) of change that may be taking place in our attitudes and values and measuring with possible experimental techniques available the degree and the effectiveness of the change; (2) and drawing up programmes of amelioration for the people. This would involve introduction of experimental situations and action programmes and legislative measures in the community. (3) Providing a basis for cross-cultural and comparative research which has a special significance in sociological research of this kind.

\section{FinANCIAL Aspects}

It would be arbitrarily to mention any specific amounts required for research in any one of the above problems but an idea can be given of the approximate expense and personnel involved. Apart from the Director of these schemes there would be at least one social scientist, two investigators and one statistician attached to each project. The incidentals would include clerical assistance (typing, cyclostyling, etc.), photographic materials and assistance, stationery, printing and travelling expenses. The total expense for each such project would be approximately 25 to 30 thousand rupees for a year.

MS. received IV 5 ' 62 .

Kali Prasad (1901- ) MA 1924 Univ. of Allahabad, 1924-1960 Prof., Dept. of Philosophy and Psychology, 1960-61 President (Vice-Chancellor), Lucknow University; 1961- Research Consultant, India International Center. 